\title{
Oligonucleotide Probe for Transcriptome in Vivo Analysis (TIVA) of Single Neurons with Minimal Background
}

Sean B. Yeldell, ${ }^{\dagger}$ Linlin Yang, ${ }^{\dagger}$ Jaehee Lee,${ }^{\ddagger}$ James H. Eberwine,${ }^{\ddagger}$ and Ivan J. Dmochowski ${ }^{*}$,

tDepartment of Chemistry, University of Pennsylvania, 231 South 34th Street, Philadelphia, Pennsylvania 19104-6323, USA

‡Department of Pharmacology, University of Pennsylvania, 38 John Morgan Building, 3620 Hamilton Walk, Philadelphia, Pennsylvania 19104-6084, USA

To whom correspondence should be addressed: ivandmo@sas.upenn.edu

\section{Contents}

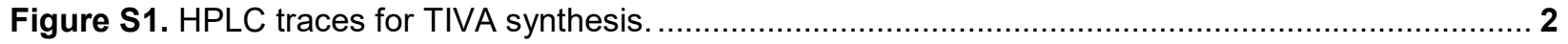

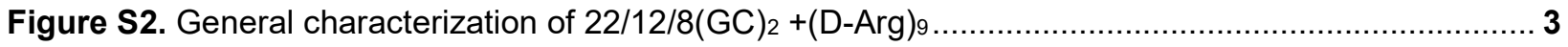

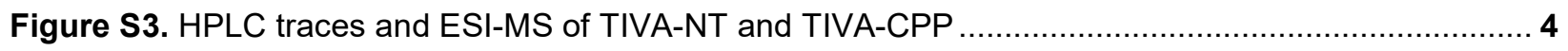

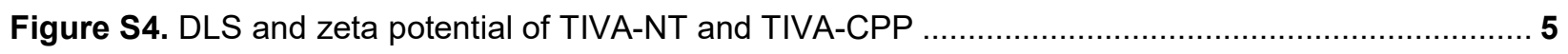

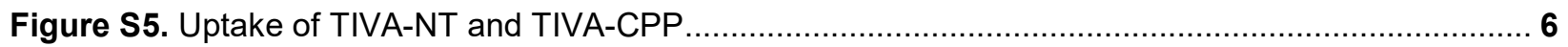

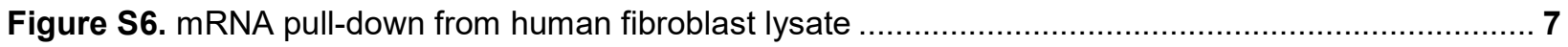

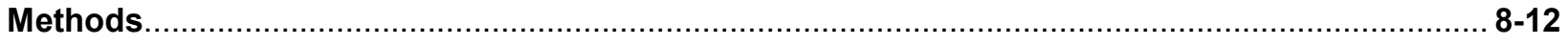

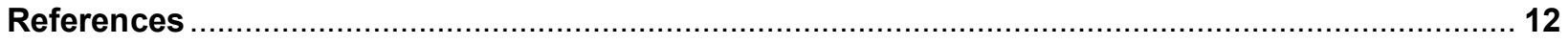


Figure S1. HPLC traces for TIVA oligo synthesis. (A) RP-HPLC purification of crude 22/12/8 (GC $)_{2}$ TIVA probe after solid-phase synthesis. (B) AX-HPLC purification of (D-Arg)9-conjugated 22/12/8 (GC)2 probe.

(A)
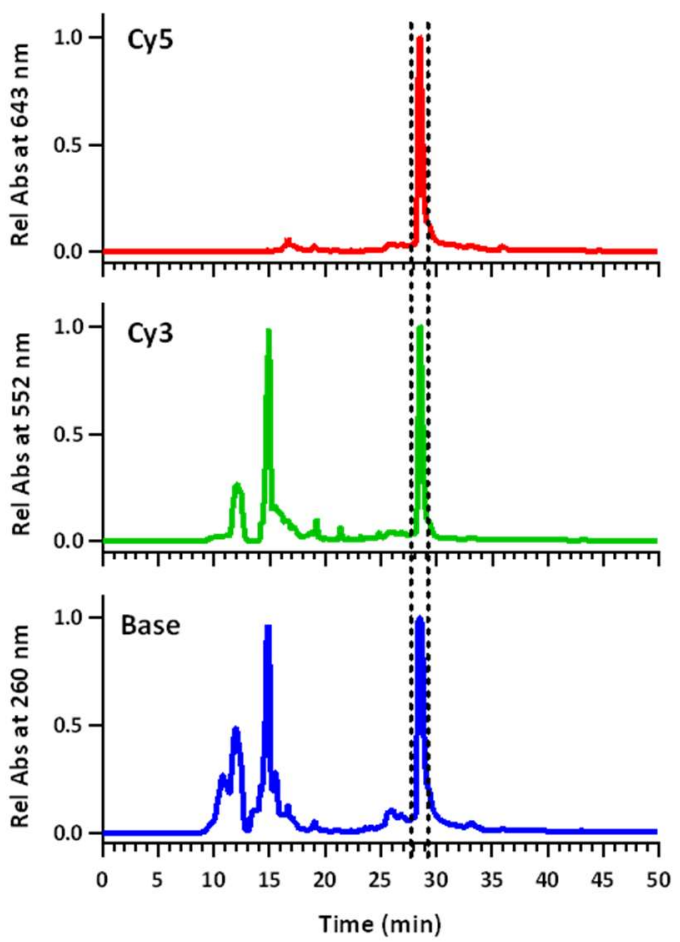

(B)
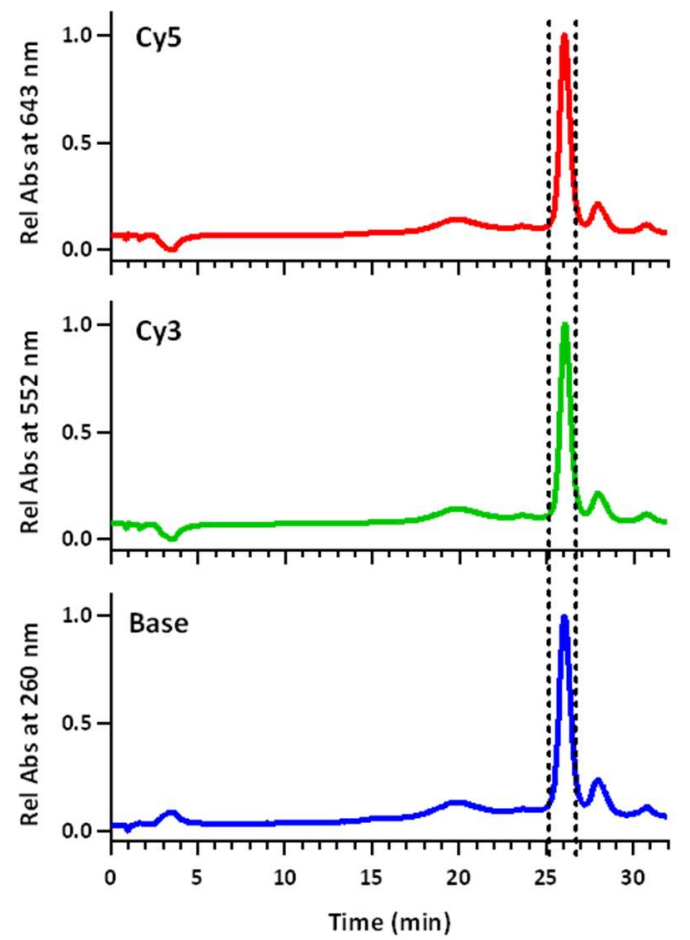
Figure S2. General characterization of 22/12/8 (GC) $)_{2}+(\mathrm{D}-\mathrm{Arg})_{9}(\mathrm{~A})$ ESI-MS (B) Melting temperature.

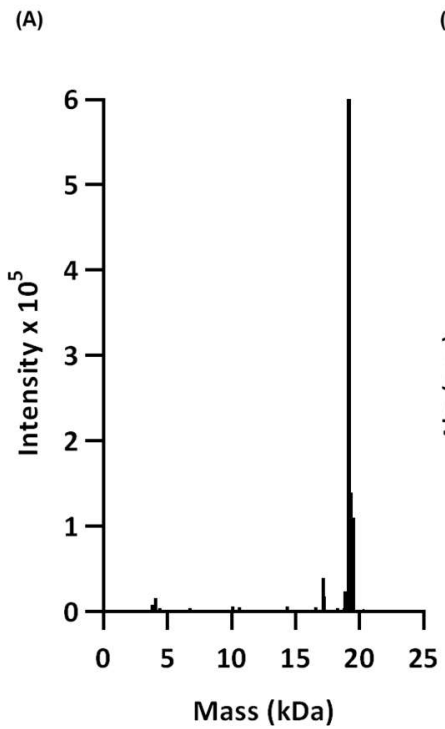

(B)

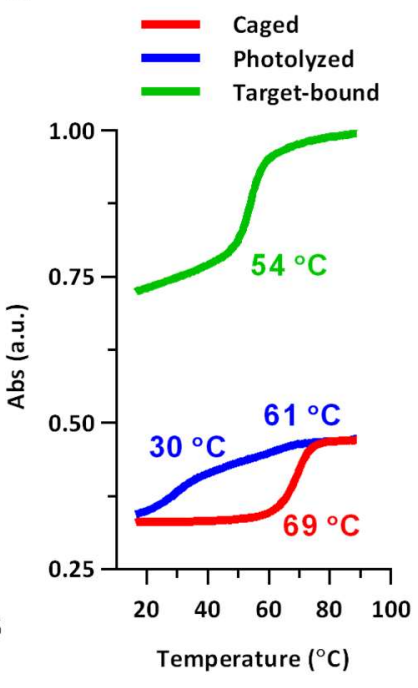


Figure S3. Synthesis and characterization of TIVA-NT and TIVA-CPP. (A) AX-HPLC purification and (B) ESI-MS of TIVA-CPP probe after (D-Arg) 9 conjugation; (C) RP-HPLC purification after DMT removal and (D) ESI-MS of TIVA-NT probe.

(A)

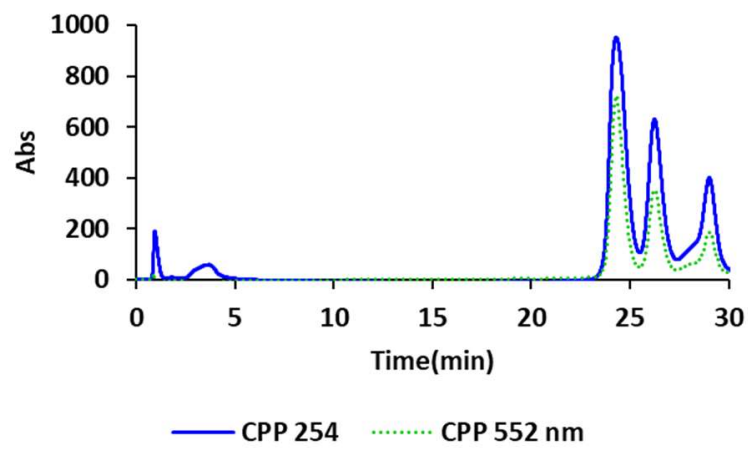

(C)

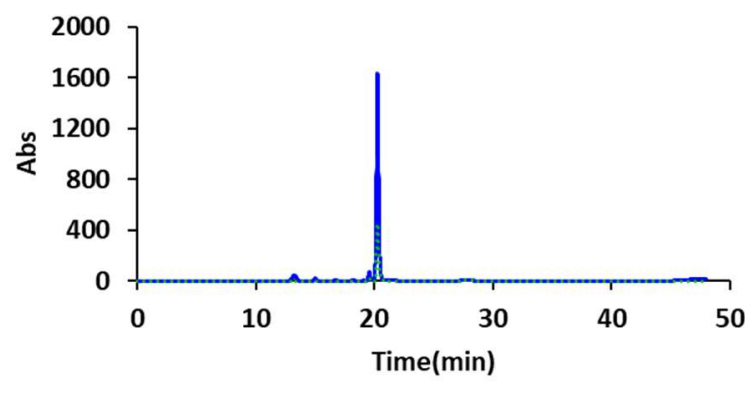

(B)

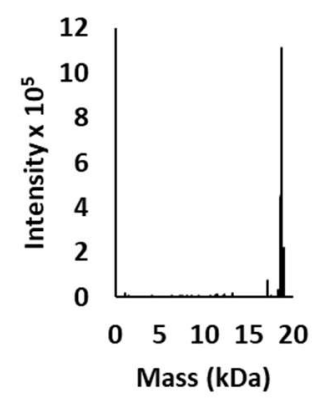

(D)

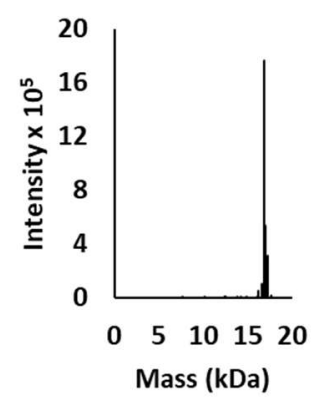

— NT no DMT $254 \mathrm{~nm} \quad \ldots \ldots \ldots .$. NT no DMT $552 \mathrm{~nm}$ 
Figure S4. (A) DLS characterization and (B) Zeta potential of TIVA-CPP and TIVA-NT at $10 \mu \mathrm{M}$ in PBS buffer $(\mathrm{pH}=7)$.

(A)

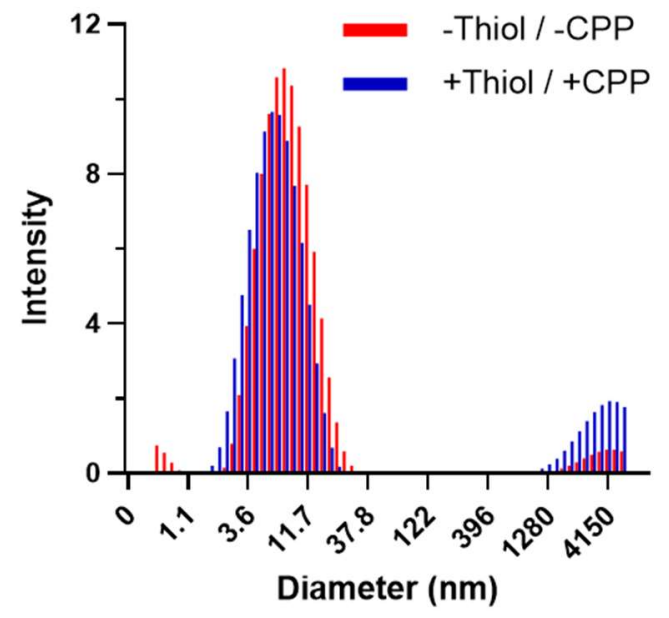

(B)

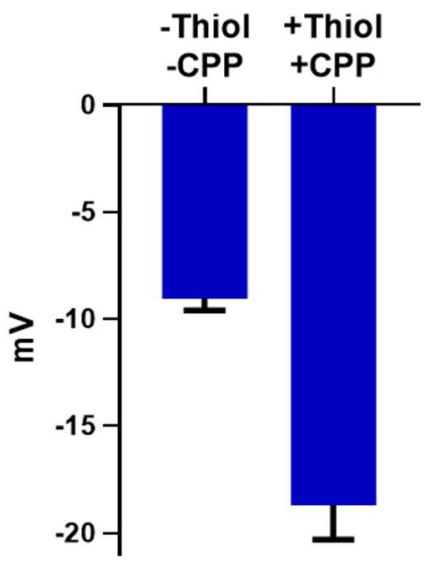


Figure S5. Uptake of TIVA-NT and TIVA-CPP monitored by Cy3 fluorescence measured by confocal laser scanning microscopy. (A) Time course fluorescence intensity (arbitrary units) for both TIVA-NT and TIVA-CPP. (B) Uptake of TIVA-CPP with treatment of amiloride.
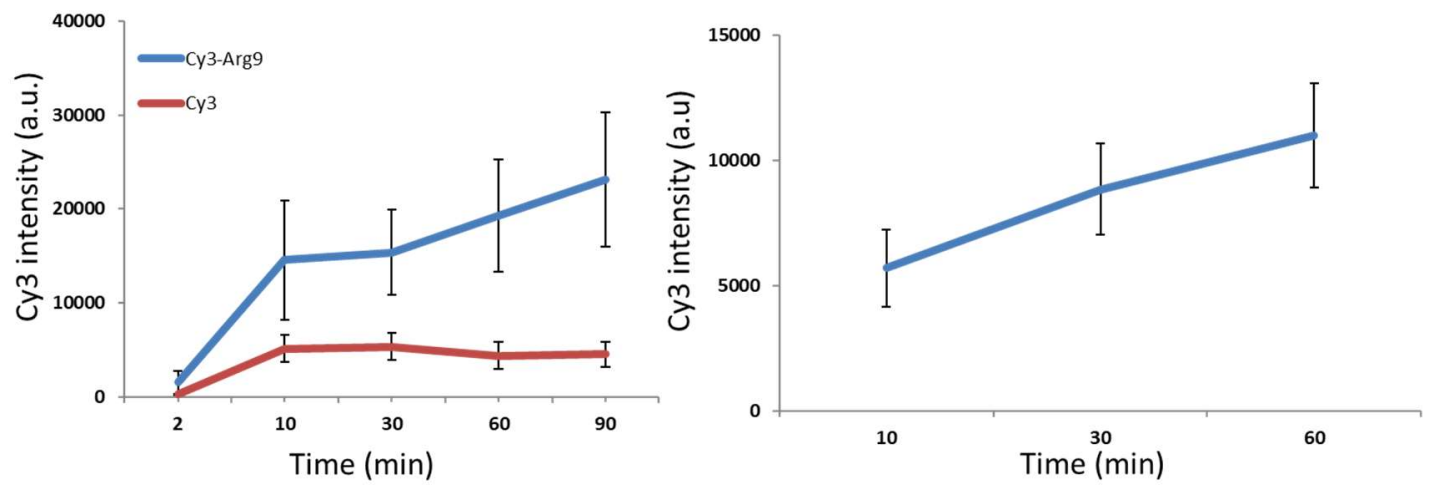
Figure S6. Concentration of mRNA from human fibroblast lysate after pull-down with unactivated ("-hv") or photoactivated 22/12/8 (GC) $2+($ D-Arg) 9 TIVA probe (“+hv"). Intensity measured on 3+ pull-down replicates using a Qubit 2.0 fluorometer.

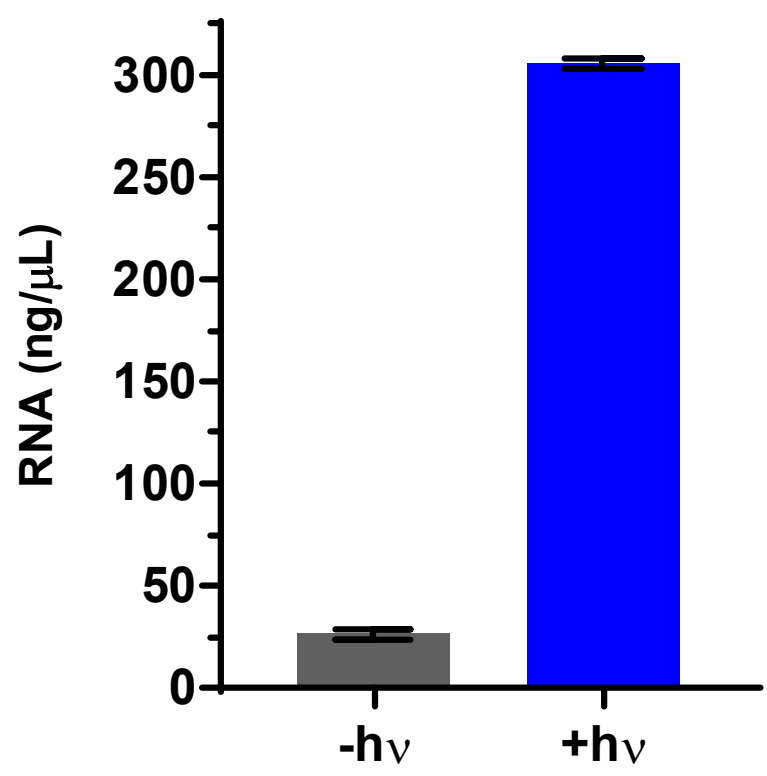




\section{METHODS}

\section{TIVA Probe Synthesis}

Synthesis of 22/12/8 (GC) $)_{2}+(\mathrm{D}-\mathrm{Arg})_{9}$ TIVA probe proceeded similarly to the published method for 22/9/9 (GC) TIVA with a few modifications. All phosphoramidites, including the TEG spacer (10-1909-XX) introduced in the 22/12/8 (GC)2 TIVA probe, were supplied by Glen Research (Sterling, VA). In brief, the oligo was synthesized by solid-phase phosphoramidite chemistry on an ABI 394 synthesizer utilizing a BiotinTEG CPG (20-2955-XX) and a 5 ' terminal DMT-capped thiol-modifier. The DMT-cap was left on during $\mathrm{NH}_{4} \mathrm{OH}$ cleavage, the $\mathrm{NH}_{4} \mathrm{OH}$ was removed by vacufuge, and the crude mixture was purified by reversephase (RP) HPLC (Agilent 1100S) on a C18 column at $1.0 \mathrm{~mL} / \mathrm{min}, 40{ }^{\circ} \mathrm{C}$. A gradient of increasing acetonitrile (B) in $0.1 \mathrm{M}$ TEAA (A) on a C18 column was employed for purification (B starting at $30 \%$, reaching $40 \%$ at $30 \mathrm{~min}, 90 \%$ at $35 \mathrm{~min}, 90 \%$ at $38 \mathrm{~min}, 30 \%$ at $46 \mathrm{~min})$. The product eluted at roughly 28 min, based upon monitoring absorbance of base (254 nm), Cy3 (552 nm), and Cy5 (643 nm) (Figure S1). After RP-HPLC purification the product was concentrated, the $5^{\prime}$ disulfide was reduced, and the released DMT-alkyl-thiol moiety was separated in a NAP-10 Sephadex column. The probe's liberated 5 ' thiol was then reacted with $1 \mu \mathrm{M}$ Cys(Npys)-(D-Arg)s peptide in formamide buffer as previously described. Anion exchange (AX) HPLC (Agilent 1100S, $1.0 \mathrm{~mL} / \mathrm{min}, \mathrm{RT}$ ) with a Resource Q column (GE Healthcare) was

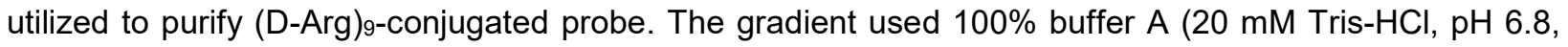
$50 \%$ formamide $)$ and $0 \%$ buffer $\mathrm{B}\left(20 \mathrm{mM}\right.$ Tris- $\mathrm{HCl}, \mathrm{pH} 6.8,50 \%$ formamide, $\left.400 \mathrm{mM} \mathrm{NaClO}_{4}\right)$ transitioning to $0 \%$ buffer $A$ and $100 \%$ buffer B over $30 \mathrm{~min}$. 22/12/8 (GC) 2 TIVA probe eluted at $26 \mathrm{~min}$. The recovered probe was buffer-exchanged to 1x STE buffer pH 8.0 (Fisher Scientific) with 4+ washes in a 10k MWCO spin column, aliquoted into $3.0 \mathrm{nmol}$ portions in amber microtubes, wrapped in foil, and stored at $-20{ }^{\circ} \mathrm{C}$ until use. The final yield for the CPP-conjugated product was $20-60 \mathrm{nmol}$, for a total yield ranging from 2 to $6 \%$, based on $A_{260}\left[\varepsilon_{260}=463,000 \mathrm{~L} /(\mathrm{mole} \cdot \mathrm{cm}\right.$ estimated via idtdna.com/calc/analyzer)] and starting scale of 1.0 umol.

TIVA-CPP was synthesized by the same method except Cy5 was not included in the sequence. Synthesis of TIVA-NT skipped the step of (D-Arg)9 peptide conjugation. Terminal DMT group was removed by $10 \%$ acetic acid for $2 \mathrm{~h}$ at rt. Acetic acid was removed by vacufuge after the reaction and the final product was desalted with NAP-5 column.

Procedures for synthesis and characterization of 22/9/9 (GC) and 18/7/7 TIVA probes were previously reported. $(1,2)$

\section{Mass Determination}

Oligonucleotide masses were determined by Novatia, LLC using a LCMS system with electrospray injection (Oligo HTCS). Analysis of 22/12/8 (GC) $2+(\mathrm{D}-\mathrm{Arg})_{9}$ verified an expected principal mass of 19,168.8 Da with an observed mass of 19,168.2 Da (Figure S2). Observed masses for TIVA-NT and TIVA-CPP were 16,914.5 Da and 18,633.8 Da (Figure S3), which matched expected masses of 16,914.1 Da and 18,635.2 $\mathrm{Da}$.

\section{$T_{m}$ and FRET Sample Preparation}

Four $60 \mu \mathrm{L}$ (FRET) or $250 \mu \mathrm{L}\left(T_{\mathrm{m}}\right)$ TIVA probe samples were prepared at $1.0 \mu \mathrm{M}$ in 1x STE buffer: two samples mixed with one equivalent of 30 mer poly-A 2'-OMe RNA as a model poly-A tail ("+polyA") and two samples without poly-A RNA ("-polyA"). One -polyA and one +polyA sample were then photoactivated ("+hv"), while the remaining two samples were left unactivated ("-hv"). Photoactivation was performed using a TL-355R Ultraviolet Transilluminator (Spectroline, Westbury, NY), irradiating the samples at $365 \mathrm{~nm}, 9$ 
$\mathrm{mW} / \mathrm{cm}^{2}$ for $8 \mathrm{~min}$, followed by brief mixing, and then irradiating for an additional $8 \mathrm{~min}$. Finally, the samples were incubated at $37^{\circ} \mathrm{C}$ for $5 \mathrm{~min}$ and then cooled to rt.

\section{Melting Point Determination}

The thermal stability of TIVA probe samples was assessed using a Beckman Coulter DU800 UV-Vis spectrophotometer and Peltier temperature controller. Samples were heated at $1.0^{\circ} \mathrm{C} / \mathrm{min}$ from $15{ }^{\circ} \mathrm{C}$ to $90{ }^{\circ} \mathrm{C}$, held at $90{ }^{\circ} \mathrm{C}$ for $10 \mathrm{~min}$, cooled at $1.0^{\circ} \mathrm{C} / \mathrm{min}$ from $90{ }^{\circ} \mathrm{C}$ back to $15^{\circ} \mathrm{C}$, and $\mathrm{A}_{260}$ was measured each minute. $T_{\mathrm{m}}$ values were assigned to each phase using first-derivative analysis.

\section{FRET Measurement}

Cy3-Cy5 FRET emission was measured on a Cary Eclipse fluorimeter (Varian) with Cary Temperature Controller (Agilent) set to $20^{\circ} \mathrm{C}$. Cy3 was excited at $552 \mathrm{~nm}$ and the emission spectrum was collected from $555 \mathrm{~nm}$ to $705 \mathrm{~nm}$. FRET efficiency was approximated using the formula FRET $=l_{a} /\left(l_{a}+\left(l_{d}^{*} \gamma\right)\right)$, where $l_{a}$ is the emission intensity of the FRET acceptor at $665 \mathrm{~nm}, l_{d}$ is the emission intensity of the FRET donor at $565 \mathrm{~nm}$, and $\mathrm{y}$ is a correction factor of 2.0 for the two fluorophores' differing quantum yields. We chose to utilize this approximation method over more complex photobleaching or single-fluorophore probe methods as it can also be used to estimate the FRET signal from TIVA probe in real-time microscopy applications.

\section{Streptavidin Bead Procedure}

Dynabeads (ThermoFisher Sci 65001) were first removed from $4{ }^{\circ} \mathrm{C}$ storage and warmed on benchtop for $30 \mathrm{~min}$ to rt. Dynabeads were vortexed for $1 \mathrm{~min}$ and an aliquot of $X \mu \mathrm{L}$ beads $(X=150 \mu \mathrm{L}$ per sample for GFP-poly(A) pull-down, later reduced to $50 \mu \mathrm{L}$ per sample for cell lysate pull-down) was removed to a LoBind $1.5 \mathrm{~mL}$ microtube (Eppendorf 022431021) and washed three times on a magnetic stand using $1 \mathrm{x}$ BW buffer [prepared as 2x BW stock: $10 \mathrm{mM}$ Tris (pH 7.5), $1 \mathrm{mM}$ EDTA, $2 \mathrm{M} \mathrm{NaCl}$ ]. Beads were fully resuspended and then allowed to settle for at least $60 \mathrm{~s}$ on the magnetic stand for each wash. As a precaution against contaminating RNA, the beads were incubated with $X \mu \mathrm{L} 0.1 \mathrm{M} \mathrm{NaOH}, 0.05 \mathrm{M} \mathrm{NaCl}$ for $2 \mathrm{~min}$, then set on the magnetic stand for $1 \mathrm{~min}$, and the wash was removed and then replaced for another 2 min treatment. The beads were then similarly incubated twice for $2 \min$ with $X \mu \mathrm{L} 0.1 \mathrm{M} \mathrm{NaCl}$, and then resuspended in the original volume of BW buffer. On the day of the pull-down experiment, to block the beads against nonspecific hydrophobic interactions an additional $X \mu \mathrm{L}$ of $10 \mathrm{ng} / \mu \mathrm{L}$ purified BSA and $0.1^{*} X$ $\mu \mathrm{L} 1 \mathrm{M}$ spermidine were added, and the bead mixture was rotated for $1 \mathrm{~h}$ at $\mathrm{rt}$. After blocking, the beads were washed three times with $1 \times$ BW buffer, and then resuspended in the original volume $(X \mu L)$ of $1 \times B W$ buffer.

\section{GFP-poly(A) RNA Expression, Pull-down, and Detection}

To obtain GFP-poly(A) transcript, pRS314-T7-GFP plasmid (Addgene ID 33130) was initially expressed in E. coli as described previously (Ping et al., 2017), and was subsequently purified by Maxiprep (Thermo Fisher Scientific) and digested with Xhol restriction enzyme for $1 \mathrm{~h}$. Linearized pRS314-T7-GFP RNA was purified by QIAquick affinity columns (Qiagen), and then T7-mediated in vitro transcription of the GFP gene was performed with a MEGAscript T7 Transcription Kit (Invitrogen) per manufacturer's protocol. GFP transcripts were polyadenylated with a Poly(A) Tailing Kit (Invitrogen AM1350) per manufacturer's instructions (Figure 6). After polyadenylation, GFP-poly(A) RNA expected 1.2-1.4 kb size was verified by capillary gel electrophoresis (Figure 6).

For pull-down, 1,500 ng of GFP-poly(A) RNA with $1 \mu \mathrm{L}$ of RNaseln in 1x STE buffer ( $5 \mu \mathrm{L}$ total) were heat denatured at $70{ }^{\circ} \mathrm{C}$ for 5 min. 10 molar eq. of 22/12/8 (GC) $)_{2}+(\mathrm{D}-\mathrm{Arg})_{9}$ TIVA probe $(1-2 \mu \mathrm{L}$ in 
STE) were added and the +light TIVA+RNA samples were placed under a transilluminator for 7 min, mixed briefly, and then irradiated for an additional $7 \mathrm{~min}$ to ensure complete photolysis. Both +light and -light tubes were incubated at $37^{\circ} \mathrm{C}$ for $5 \mathrm{~min}$, and then placed on ice. To each $\sim 7 \mu \mathrm{L}$ TIVA probe+RNA sample, 0.6 $\mu \mathrm{L} 1 \mathrm{M}$ spermidine and $150 \mu \mathrm{L}$ of blocked beads were added, and the mixtures were rotated for $40-60 \mathrm{~min}$ at $18{ }^{\circ} \mathrm{C}$. After binding, the tubes were placed on a magnetic stand for $3 \mathrm{~min}$, and the supernatant was subsequently discarded. Bead pellets were washed three times with $200 \mu \mathrm{L}$ of ice-cold 1x BW buffer to remove unbound material. During these washes, the bead pellets were gently rinsed while bound to the magnetic stand but the pellets were not fully re-solubilized, allowing only $30 \mathrm{~s}$ to lightly settle after each wash. Finally, the beads were resuspended in $120 \mathrm{uL}$ of nuclease-free water with $1 \mu \mathrm{L}$ of Rnaseln, and captured mRNA was released by incubating at $70{ }^{\circ} \mathrm{C}$ for $5 \mathrm{~min}$. Heated tubes were immediately transferred to the magnetic stand and allowed to settle for $2 \mathrm{~min}$, and $118 \mu \mathrm{L}$ of the eluent was collected to avoid transferring any beads left at the bottom of the tube. To further eliminate any residual beads, the $118 \mu \mathrm{L}$ eluent tubes were placed back onto the magnetic stand, and after 2 min an aliquot (116 $\mu \mathrm{L})$ was transferred to fresh Lobind tubes. $5 \mu \mathrm{L}$ of $100 \mathrm{mM} \mathrm{NaCl} / 75 \mathrm{mM}$ Tris buffer was added, and the solutions were concentrated to $10 \mu \mathrm{L}$. $1 \mu \mathrm{L}$ of this solution was loaded onto a Bioanalyzer Nanochip, and the electrophoresis was performed according to manufacturer's instructions.

\section{Fibroblast Culture, Lysis Preparation, Pull-down, and Detection}

CCD-1112Sk human neonatal foreskin-derived fibroblasts (ATCC, Manassas, VA) were cultured in IMDM with $10 \%$ FBS and penicillin/streptomycin in a $37{ }^{\circ} \mathrm{C}$ incubator with $5 \% \mathrm{CO}_{2}$. For pull-down experiments fibroblasts were seeded into wells of a 24-well plate and grown to confluency overnight. On the day of the pull-down experiment the wells were gently washed twice with $400 \mu \mathrm{L}$ of PBS buffer, and then incubated with $250 \mu \mathrm{L}$ of $0.5 \%$ trypsin at $37^{\circ} \mathrm{C}$ for $5 \mathrm{~min} .750 \mu \mathrm{L}$ IMDM media with $10 \%$ FBS was added to quench the trypsinization, and the cell mixtures were transferred to individual sterile Lobind $1.5 \mathrm{~mL}$ tubes. Cell mixtures were centrifuged at $15,000 \mathrm{~g}$ for $5 \mathrm{~min}$ and washed with $200 \mu \mathrm{L}$ PBS, then $5 \mu \mathrm{L}$ RNaseln were added followed by $50 \mu \mathrm{L}$ of ice cold $5 x$ First-Strand buffer $(250 \mathrm{mM}$ Tris-HCl, pH 8.3, $375 \mathrm{mM} \mathrm{KCl}, 15 \mathrm{mM}$ $\mathrm{MgCl}_{2}$ ). To aid in lysis, tubes were snap-frozen in liquid nitrogen and then thawed, and this freeze-thaw cycle was performed twice. Fibroblast lysate tubes were set aside on ice.

Aliquots of $200 \mathrm{pmol}$ of 22/12/8 (GC) $)_{2}+(\mathrm{D} \text {-Arg) })_{9}$ TIVA probe in $50 \mu \mathrm{L}$ PBS were incubated at 37 ${ }^{\circ} \mathrm{C}$, while +light samples were irradiated for $5 \mathrm{~min}$ under a $410 \mathrm{~nm}$ LED. TIVA aliquots were combined with lysate aliquots, and $50 \mu \mathrm{L}$ blocked beads and $100 \mu \mathrm{L}$ of $1 \times$ BW buffer were added to each tube, and the mixtures were rotated at $18{ }^{\circ} \mathrm{C}$ for $40-60 \mathrm{~min}$. Tubes were then washed three times with ice-cold $1 \mathrm{x}$ BW buffer as described earlier, before being resuspended in $25 \mu \mathrm{L}$ of nuclease-free water for elution at $70^{\circ} \mathrm{C}$ for $5 \mathrm{~min}$. The eluent was returned to the magnetic stand and $23 \mu \mathrm{L}$ captured in fresh Lobind tubes. The concentration of RNA in these tubes was later assessed on a Qubit 2.0 fluorescence detector according to manufacturer instructions.

\section{DLS and Zeta Potential}

Hydrodynamic diameter of TIVA complexes was determined by dynamic light scattering (DLS) and zeta potential by Laser Doppler Velocimetry (LDV) at $25^{\circ} \mathrm{C}$ using a Zetasizer Nano ZS apparatus (Malvern Panalytical). TIVA probes lacking Cy5, with or without CPP (TIVA-CPP, TIVA-NT) were prepared in PBS buffer diluted to $10 \mu \mathrm{M}$. We determined that Cy5 interfered with these measurements, due to significant absorbance of the $633 \mathrm{~nm}$ light used for sample interrogation, but Cy3 did not. Samples were assessed in disposable low-volume cuvettes protected from ambient light. Each sample was measured 3 times and data presented in 'relative intensity'. Zeta potential was also measured by the same instrument. Samples were prepared in water at $2 \mu \mathrm{M}$ in Folded Capillary Zeta Cell (Malvern Panalytical) protected from ambient light. Each sample was measured 3 times. 


\section{Stability Assay}

TIVA 22/12/8 and TIVA 18/7/7 probes were diluted to $1.0 \mu \mathrm{M}$ in PBS and incubated at $37{ }^{\circ} \mathrm{C}$ for $24 \mathrm{~h}$ with or without $10 \%$ FBS. Cy 3 emission at $565 \mathrm{~nm}$ and Cy 5 emission at $665 \mathrm{~nm}$ were recorded every 10 min by the Infinite ${ }^{\circledR}$ M1000 plate reader (Tecan). FRET efficiencies were calculated as indicated above. FRET efficiency at each time point was normalized to the starting point.

\section{TIVA Probe Loading into Cells and Activation}

The cortical brain slices $(250 \mu \mathrm{m})$ were prepared from 30 50 day old freshly isolated C57BL/6 mouse brain using a vibratome (Leica VT 2000). The brain slices were incubated in artificial cerebrospinal fluid (aCSF, in $\mathrm{mM}: \mathrm{NaCl} 122, \mathrm{CaCl}_{2} 2, \mathrm{NaHCO}_{3} 28, \mathrm{KCl} 3.5$, glucose 5.5, HEPES 10, $\mathrm{MgCl}_{2} 1, \mathrm{pH} 7.4$ with $5 \% \mathrm{CO}_{2} /$ $95 \% \mathrm{O}_{2}$ gas) for $30 \mathrm{~min}$ followed by loading of the 22/12/8 (GC) $)_{2}+(\mathrm{D}-\mathrm{Arg})_{9}$ TIVA probe into cells by incubation with the $3 \mu \mathrm{M}$ TIVA-probe in aCSF for $90 \mathrm{~min}$ at rt. After loading, excitation and uncaging was performed while imaging the FRET signal by $514 \mathrm{~nm}$ excitation and simultaneous capturing of images in the Cy3 (538-599nm) and Cy5 (637-704nm) emission ranges. The photolysis was performed in visually identified cells in the cortex while live tissue/cell imaging on the confocal microscope (Zeiss 710meta) using a laser power at $80 \%$ and $100.85 \mu \mathrm{s}$ dwell time per pixel. After uncaging, the targeted region including adjacent cells was isolated using a glass pipet and the TIVA/RNA hybrids isolated and the RNA processed for sequencing.

\section{TIVA Probe Uptake}

The cellular uptake was tested with mouse brain slices in aCSF prepared as mentioned. $3 \mu \mathrm{M}$ TIVA-NT or TIVA-CPP was loaded to brain tissue samples. Uptake was shown by Cy3 intensity and imaged under a confocal microscope (same setting). Images were taken at 2, 10, 30, 60, $90 \mathrm{~min}$. For amiloride study, cells were pre-incubated in aCSF with $10 \mathrm{mM}$ amiloride for $30 \mathrm{~min}$, and TIVA-CPP was loaded in the abovementioned way. Confocal images were taken at 10, 30, $60 \mathrm{~min}$.

\section{TIVA aRNA Amplification, Library Construction and Sequencing}

As the TIVA/RNA complex is tagged with a biotin moiety, the complex can be isolated using streptavidin to bind to the biotin in the complex. To accomplish this, Dynabeads MyOne Streptavidin C1 (Thermo Fisher Scientific, Catalog \#65001) were washed according to the manufacturer's instructions, and resuspended in Binding and Washing (B\&W) Buffer (5 mM Tris-HCl, pH 7.5, $0.5 \mathrm{mM}$ EDTA, $1 \mathrm{M} \mathrm{NaCl}$ ). The Dynabeads were blocked by rotating desired volume of the blocking mixture $(0.2 \mu \mathrm{g} / \mu \mathrm{L}$ washed Dynabeads, $4 \mathrm{ng} / \mu \mathrm{L}$ BSA, $4 \mathrm{mM}$ spermidine) at $\mathrm{rt}$ for $1 \mathrm{~h}$. Blocked Dynabeads was then washed with B\&W buffer for three times, and resuspended in $B \& W$ buffer to the final concentration of $10 \mathrm{mg} / \mathrm{mL}$. The collected target cell was mixed with $60 \mu \mathrm{L} \mathrm{B \& W}$ buffer, $0.3 \mu \mathrm{L} 1 \mathrm{M}$ spermidine, $1 \mu \mathrm{L}$ blocked Dynabeads and rotated for $30 \mathrm{~min}$ at $12{ }^{\circ} \mathrm{C}$ with vortexing at $5 \mathrm{~min}$ intervals. The tube was then placed onto a magnetic stand for $3 \mathrm{~min}$ and the pellet was washed 3 times with $12{ }^{\circ} \mathrm{C} \mathrm{B \& W}$ buffer. After air-drying for 3 min, Dynabeads were resuspended in 6 $\mu \mathrm{L}$ water and incubated at $70{ }^{\circ} \mathrm{C}$ for $5 \mathrm{~min}$. The suspension was placed on magnetic stand for 2 min and 5 $\mu \mathrm{L}$ of deannealed solution containing the cellular RNA was used as template for two rounds of aRNA amplification (1). A 1:4 million dilution of ERCC RNA Spike-In (Life Technologies) was added to each sample to control for technical variation between samples. Briefly, for the first round of amplification, a synthesized oligo(dT)-T7 primer that contained a poly-T and phage T7 RNA polymerase promoter 
sequence was hybridized to the mRNA in the sample and used to create double-stranded cDNA. The T7 promoter included in the oligo was used to initiate T7 polymerase-mediated linear amplification of the RNA. For second round of amplification, aRNA was converted into cDNA initiated by random hexanucleotide primers for first strand and oligo(dT)-T7 primer for second strand. The amplified aRNA was purified and then assessed using Bioanalyzer RNA Pico kit (Agilent, Catalog \#5067-1513). This material was then made into a sequencing library using Illumina TruSeq Stranded mRNA library Prep kit (Catalog \#20020594) according to the manufacturer's instructions and submitted for NextSeq550 sequencing. These protocols were adapted from Lovatt et al. $(2,3)$

\section{References}

(1) Yeldell, S. B., Ruble, B. K., and Dmochowski, I. J. (2017) Oligonucleotide modifications enhance probe stability for single cell transcriptome in vivo analysis (TIVA). Org. Biomol. Chem. 15, 10001-10009.

(2) Lovatt, D., Ruble, B. K., Lee, J., Dueck, H., Kim, T. K., Fisher, S., Francis, C., Spaethling, J. M., Wolf, J. A., Grady, M. S., Ulyanova, A. V., Yeldell, S. B., Griepenburg, J. C., Buckley, P. T., Kim, J., Sul, J. Y., Dmochowski, I. J., and Eberwine, J. (2014) Transcriptome in vivo analysis (TIVA) of spatially defined single cells in live tissue. Nat. Methods 11, 190-196.

(3) Morris, J., Bell, T. J., Buckley, P. T., and Eberwine, J. H. (2014) Antisense RNA amplification for target assessment of total mRNA from a single cell. Cold Spring Harb. Protoc. 2014, 1149-1160. 